\title{
"Em Meu Gesto Existe o Teu Gesto": Corporeidade na Inclusão de Crianças Deficientes
}

\author{
In My Gesture is Your Gesture: Inclusion of Disabled Children in School
}

\author{
Fabio Scorsolini-Comin ${ }^{*}, a$ \& Katia de Souza Amorim ${ }^{b}$ \\ ${ }^{a}$ Universidade Federal do Triângulo Mineiro \& Universidade de São Paulo ${ }^{b}$
}

\begin{abstract}
Resumo
Objetivou-se investigar a questão da corporeidade (inerente relação corpo-mente-outro-ambiente) de crianças com Paralisia Cerebral, em processos de inclusão, por meio de transcrições de videogravações em ambiente escolar. Com base na perspectiva da Rede de Significações, à análise microgenética das cenas de interação, a corporeidade revela-se por meio dos lugares onde essas crianças são colocadas, do modo como os adultos as tratam e como elas reagem, bem como das práticas discursivas sobre educação, inclusão e deficiência presentes. O olhar dos outros derivam das e simultaneamente orientam as práticas e concepções que são construídas contínua e mutuamente em situadas relações entre essas crianças e os outros, em função e a partir de seus corpos, produzindo significações, posições e identidades sociais de modo dinâmico.

Palavras-chave: Corporeidade; Dialogismo; Inclusão; Paralisia Cerebral.
\end{abstract}

\begin{abstract}
The aim of this paper is to present a study regarding the embodiment issue (body-mind-other-context relationship), through the investigation of the inclusion of two children with cerebral palsy in school. Based on the Network of Meanings perspective, microgenetic analysis of video recording transcriptions revealed embodiment through the places where such children are put in, through the ways adults treat them and how they react as well as by the discourse practices regarding education, inclusion processes and deficiency. The others' perceptions and glances simultaneously derive from and give directions to the practices and conceptions used. They are continuously and mutually constructed in relations between children and others which are related to the children's and adults' bodies and conceptions; dynamically producing significations, positions and social identities.

Keywords: Embodiment; Dialogism; Inclusion; Cerebral Palsy.
\end{abstract}

O problema das relações entre mente, corpo e ambiente tem representado um tema controverso, ao longo da história da humanidade, adquirindo diferentes enfoques conforme o período histórico analisado, além dos diversificados aspectos discursivo-culturais de um mesmo período histórico e/ou grupo social (Amorim, 2002).

Na Psicologia do Desenvolvimento e Psicologia Cultural, autores como Fogel (2000), Overton (1997) e Valsiner (1987) discutem que, de maneira geral, pesquisadores têm separado seus objetos de estudo - pessoas - dos ambientes que os rodeiam, muitas vezes estudando o fenômeno psicológico em separado do contexto, como se fossem independentes.

\footnotetext{
*Endereço para correspondência: Universaidade Federal do Triângulo Mineiro, Av. Getúlio Guaritá, 159, Abadia, CEP 38025-440, Uberaba, MG. A/C Fabio ScorsoliniComin (Curso de Psicologia). E-mail: scorsolini@psicologia.uftm.edu.br

${ }^{1}$ Vinícius de Moraes. In: A. Bueno (Org.). Poesia completa e prosa. Rio de Janeiro: Nova Aguilar, 1998.
}

No contraponto a uma abordagem dicotômica, alguns referenciais, como a perspectiva teórico-metodológica da Rede de Significações ou RedSig (Rossetti-Ferreira, Amorim, Silva, \& Carvalho, 2004), têm pontuado que as dimensões pessoa e ambiente devam ser concebidas como indissociáveis e mutuamente constitutivas. Nessa perspectiva, o(s) outro(s) sociais e o contexto apresentam um papel fundamental na constituição e desenvolvimento da pessoa. Segundo a mesma, dentro de um deter-minado contexto, concomitantemente, as pessoas se mostram submetidas às características dele, assim como são ativas e o constituem, de modo geral contrapondose, negociando e/ou reconstruindo os limites e as possibilidades colocadas a partir dele.

Concebendo desenvolvimento a partir de uma perspectiva sistêmica, aquele processo é compreendido, nessa perspectiva, como se dando na e através da inter-relação entre os componentes individuais, contextos e campos interativos. Essa intrínseca articulação representa a base da proposta de metáfora de rede. Ainda, dadas essas 
articulações, em um jogo dinâmico, transformações em elementos das mesmas podem vir a reconfigurar a rede. Essa reconfiguração se dá em um jogo de figura-fundo, em que determinados elementos se destacam, ficando outros latentes. Levam, com isso, a uma dinâmica entre repetição e transformação, a partir dos quais se dá a manutenção/transformação de ações, sentimentos e pensamentos nas pessoas, em suas relações e em seus meios. É neste interjogo que atuam várias vozes, vários discursos, que tanto conferem o caráter de multiplicidade à constituição da pessoa (já que são vários outros que atuam em seu desenvolvimento), quanto conferem um caráter dinâmico a estas redes de significações, em que diferentes signos podem vir a emergir. Nessa articulação eu-outro-contexto, destaca-se o lugar da alteridade no desenvolvimento, o que leva ao resgate da noção de dialogismo. Particularmente nesta abordagem, considera-se a noção de dialogismo fundamentada no pensamento de Bakhtin (1997, 1999).

O russo Mikhail Bakhtin, partindo da Linguística, compartilhou com os teóricos marxistas de um interesse pelo mundo histórico e social, investigando como os seres humanos agem e pensam. E, para ele, a pessoa inerentemente emerge na relação com o outro. De acordo com Faraco (1996), o pensamento bakhtiniano permite uma compreensão radical da alteridade, pois apresenta uma visão multirreferenciada, na qual tempo e espaço estão em constante interação no processo de construção eu/ outro. Nesse sentido, a concepção dialógica contém a ideia da relatividade da autoria individual e, por conseguinte, o destaque do caráter coletivo e social da produção de discursos. Assim, é possível entender o outro de uma maneira original, pois ele é referido não como alguém que está fora de mim, que é estranho a mim, mas como alguém que me constitui, que contribui para o processo de construção de um eu que não me pertence integralmente e que somente existe a partir do olhar do outro.

Apesar de partir da e ter foco na Linguística, segundo Bakhtin (1999), não apenas a linguagem verbal é relevante e portadora de significação. Todo gesto ou processo do organismo, como a respiração, a circulação sanguínea, os movimentos do corpo, a articulação, o discurso interior, a mímica, a reação aos estímulos exteriores, enfim, tudo o que ocorre no organismo pode tornar-se material para a expressão da atividade psíquica. Posto que tudo pode adquirir um valor semiótico, tudo pode tornar-se expressivo (Bakhtin, 1997). Destaca-se, assim, o gesto e a expressividade corporal enquanto constituintes do processo relacional com o outro e, portanto, do próprio desenvolvimento, colocando em destaque o papel do próprio corpo (ou da pessoa corporificada) na relação com o outro/meio. Para tratarmos desse aspecto, para o qual Bakhtin aponta em seus trabalhos, mas não aprofunda (inclusive em função da área a que estava ligado - Linguística) passaremos a nos remeter à noção de corporeidade (embodiment).

\section{A Noção de Corporeidade}

Essa noção vem sendo elaborada mais particularmente nas últimas décadas, podendo ser considerada como uma concepção que, simultaneamente, contempla e extrapola o conceito de dialogismo, permitindo deslocar a noção vinda da Linguística, para o campo da Psicologia do Desenvolvimento.

De modo a se compreender com maior clareza essa noção de corporeidade, foi realizado extenso levantamento bibliográfico na literatura científica nacional e internacional (Scorsolini-Comin, \& Amorim, 2008). Neste, constatou-se a complexidade do estudo sobre a corporeidade, salientando as múltiplas vozes e campos presentes quando se aborda o tema. Verificaram-se diferentes enfoques e sentidos dados à noção, sendo que aqueles se dispõem em construção, simultaneamente contribuindo para constituir todo um novo olhar para o corpo e o desenvolvimento humano (Scorsolini-Comin, 2006; ScorsoliniComin, \& Amorim, 2008). Hoogland (2002) explicita o atual interesse na questão da corporeidade, referindo esse se dar, entre outros, pelos recentes avanços biomédicos e tecnológicos, apesar de que o termo ainda representa um conceito enigmático da pós-modernidade.

A corporeidade é, no entanto, vista para além do ponto de vista biológico, sendo interpenetrada fortemente pela cultura, pelas políticas e pelas práticas sociais. Mais ainda, Paterson e Hughes (1999) consideram o corpo/ corporeidade enquanto algo ativo, como produtor de discursos. Hoogland (2002), nesse sentido, destaca a contribuição merleau-pontyana de romper com a visão mecanicista de corpo - que o vê em termos de suas partes e funções, não o considerando enquanto totalidade em constante interpenetração com o mundo (cultura, sociedade, alteridade). Aquele autor destaca também a necessidade de envolver simultaneamente os aspectos materiais e não materiais de nossa experiência, atentando para as teorias culturalistas, pelas quais se pode discutir pessoa e contexto. Dessa forma, o corpo enquanto corporeidade indica que a forma como a pessoa sente seu corpo, como o experiencia, é temporal e espacialmente específica.

Nesse sentido, Polak (1997) traz o propósito de um corpo que ocupa o lugar de fusão de fenômenos orgânicos e sociais, sendo o cenário no qual a cultura e a natureza dialogam, onde o coletivo e o individual se interpenetram. O ser humano se faz presente no mundo pelo seu corpo, este último representando uma dimensão construtiva e expressiva do ser do homem, sendo denominado de corpo próprio, corpo vivente. Deste modo, Polak (1997), apoiando-se nas ideias de Merleau-Ponty, concebe o corpo como algo que percebe e é simultaneamente percebido, devendo ser compreendido não apenas como objeto. Este conceito de "corpo vivente" ou "corpo vivido" seria uma forma de se estar no mundo em relação com os outros e com as coisas. Esta noção coloca a centralidade da alteridade, na medida em que a corpo- 
reidade se dá na relação com o mundo, na qual o outro nos constitui e ao qual constituímos continuamente.

No presente estudo, compartilhamos dessa noção e, particularmente, da definição de corporeidade de Polak (1997), que a coloca como uma noção que vai além da materialidade do corpo, contemplando várias das dimensões da existência. Compartilhamos, ainda, da noção de intercorporeidade (Coelho Júnior, 2003), que destaca o "eu" e o "outro" como partes constituintes da mesma corporeidade. Desse modo, a corporeidade é aqui investigada em seus aspectos relacional, social, cultural e histórico, representando um palco de expressão de vivências, interações e discursividades.

A análise geral da revisão bibliográfica pode verificar a complexidade que envolve essa noção. Além disso, um ponto identificado foi o fato de que ela é muito pouco explorada no campo da Psicologia do Desenvolvimento. Mais ainda, ela é fundamentalmente trabalhada teoricamente, sem se embasar em estudos empíricos. Nesse sentido, entendeu-se que um desafio continuava colocado na área: como investigar e apreender processos desenvolvimentais humanos, em que se preserve o estudo de tais processos como se dando inerentemente de forma relacional e situada? E, ainda, que busque apreender tais processos incluindo-se aí o papel do corpo.

$\mathrm{O}$ objetivo geral da pesquisa foi investigar processos desenvolvimentais, estudando de modo integrado a pessoa e o ambiente, destacando a corporeidade ( $\mathrm{em}$ bodiment) por meio das relações da criança com o(s) outro(s) sociais, bem como a partir das formas de cuidado, das concepções e das práticas discursivas presentes. Para este objetivo, optou-se por estudar crianças diagnosticadas com Paralisia Cerebral e que se encontrassem em processo de inclusão escolar.

A fim de se ter mais claros alguns aspectos das redes de significações de que essas crianças fazem parte, antes de apresentar o estudo empírico propriamente dito, abordar-se-á um pouco a respeito do seu quadro clínico (Paralisia Cerebral) e de como vem sendo colocada a discussão dos processos escolares inclusivos.

\section{A Paralisia Cerebral}

Yazlle, Amorim e Rossetti-Ferreira (2004) indicam que, segundo a Organização Mundial da Saúde, a Paralisia Cerebral é definida como uma deficiência física que tem sua origem em uma lesão cerebral que ocorreu durante o nascimento da criança, ou ainda logo antes ou após o mesmo. De acordo com as autoras, há um relativo consenso de que haja várias causas dessa patologia, as quais levam à anóxia na criança. A depender da gravidade e do momento de desenvolvimento em que esta ocorre, os quadros clínicos podem se manifestar de diferentes formas. Possivelmente por esse aspecto, existem várias classificações para essa patologia, as quais foram constituídas de acordo com a fisiologia e topografia das áreas e funções afetadas. A Paralisia Cerebral, nesse sentido, constitui-se como um componente individual (orgânico) fortemente circunscritor, o qual articulado a outros elementos vão conferir diversificados limites e possibilidades de ação/apreensão sobre a/da realidade, contribuindo para constituir o desenvolvimento da criança.

Tomando a RedSig como base, entende-se que tal desenvolvimento seja marcado pelas significações que emergem do entrelaçamento dessas características pessoais com as práticas discursivas sobre deficiência, eficiência e diferença; e, ainda, de quem e do que educar, considerando-se a função da escola. Isto é, remete a questões ligadas aos aspectos sócio-culturais relacionados à educação e à educação de crianças com esse quadro, o que coloca em discussão os contemporâneos processos de inclusão social e escolar.

\section{Os Processos de Inclusão}

Segundo Roriz, Amorim e Rossetti-Ferreira (2005), o movimento em defesa de uma sociedade inclusiva assume maior destaque, na segunda metade do século XX, momento em que se desencadeia um processo geral de reflexão e crítica sobre os direitos humanos relacionados às minorias. No sentido do respeito a questões éticas e de direitos humanos, passou-se então a traçar metas para a equalização de oportunidades para as pessoas com necessidades especiais. Importantes marcos para o fortalecimento desse discurso foram a concepção de sociedade inclusiva (Resolução 45/91, da Organização das Nações Unidas [ONU], 1990) e a Declaração de Salamanca (1994). Como o Brasil é signatário dessas declarações, aparecem reflexos dessa visão na Constituição da República Federativa do Brasil (1988) e na Lei de Diretrizes e Bases (Lei n. 9.394, 1996), as quais, por exemplo, dispõem que as crianças com necessidades especiais devam preferencialmente frequentar salas de aula do ensino regular.

No Brasil, essa política de Educação Inclusiva foi introduzida nas políticas públicas do sistema educacional brasileiro por meio de uma série de documentos, parâmetros e leis. Porém, verifica-se que, historicamente, este é um movimento recente, estando atravessado por diferentes práticas e concepções oriundos de diferentes períodos históricos e processos sociais. Isso faz com que o proposto processo de inclusão se mostre permeado por polissêmicos discursos, por uma série de práticas discursivas polêmicas e, até mesmo, conflituosas (Roriz, Amorim, \& Rossetti-Frreira, 2005). Tendo dito isso, passemos às considerações do estudo empírico.

\section{Método}

\section{Procedimento}

O Banco de Dados. A investigação foi realizada a partir do estudo de caso (Yin, 2005) de duas crianças com Paralisia Cerebral, em processos de inclusão préescolar no ensino regular, da região de Ribeirão Preto (SP), durante o ano de 1999. O material empírico foi obtido do Banco de Dados do Projeto "Pré-escolas con- 
vivendo com a Paralisia Cerebral: uma análise do processo de inclusão/exclusão" (Yazlle, 2001), que acompanhou os processos de inclusão pré-escolar de quatro crianças com Paralisia Cerebral. Na presente investigação, trabalhamos com duas dessas crianças, as quais serão descritas a seguir.

Registros da Situação. Gravações em vídeo (VHS) referentes às crianças, no ambiente pré-escolar, além de informações obtidas a partir de entrevistas com os pais, com os profissionais de saúde, além de funcionários das instituições de ensino, nas quais foram feitas as gravações. Para este trabalho, foram utilizadas, mais especificamente, as gravações em vídeo.

Construção e Análise do Corpus de Investigação. Todas as cenas das duas fitas de VHS (uma de cada criança) foram transcritas, sendo as anotações divididas por ambiente (refeitório, parque e sala de aula). A análise microgenética (Góes, 2000) das cenas foi conduzida com base na perspectiva teórico-metodológica da Rede de Significações (Rossetti-Ferreira et al., 2004; RossettiFerreira, Amorim, Soares-Silva, \& Oliveira, 2008), apresentada na introdução deste trabalho.

\section{Participantes}

Participaram do estudo duas meninas - Issa e Laura (nomes fictícios), com quatro anos de idade, diagnosticadas com Paralisia Cerebral. Além destas, também foram considerados como sujeitos participantes os seus respectivos pais, educadores, funcionários e demais crianças da pré-escola, além dos profissionais de saúde e dos pesquisadores envolvidos. Apresentar-se-ão os casos das duas crianças acompanhadas neste estudo. Do conjunto, algumas cenas foram selecionadas para serem aqui discutidas, particularmente as que aconteceram no refeitório.

\section{Resultados e Discussão}

\section{O Estudo de Caso de Issa}

Issa tem quatro anos de idade e é filha de pais que são primos, sendo de uma família de camada média-baixa. Ela é uma criança magra, com estatura própria da idade. O diagnóstico clínico é referido como de "paralisia cerebral atetóide" (variações do tônus muscular e com movimentos involuntários). Devido à Paralisia Cerebral, músculos de seu rosto ficaram comprometidos, o que faz com que ela fique com a boca aberta a maior parte do tempo, contribuindo para a falta de controle de perda de saliva. Nas gravações, não é possível vê-la falando, mas apenas emitindo curtas e esparsas vocalizações. Não possui pleno controle esfincteriano. Tem dificuldades para manusear objetos e apresenta desequilíbrio ao caminhar, apesar de possuir autonomia para a locomoção.

As cenas aqui apresentadas ocorreram no refeitório da pré-escola, após pouco mais de um mês de iniciado o processo de frequência de Issa à instituição. Delas participam seus colegas de classe, bem como a educadora e a cozinheira. Primeiramente, descrever-se-ão os episódios, seguindo-se depois à análise dos mesmos.

Episódio 1. Issa no Refeitório da Pré-Escola: "Entrando pelos Fundos." Issa entra no refeitório antes de seus colegas, pelo lado oposto ao dos outros alunos. Enquanto ela entra e se senta, as demais crianças aguardam em fila, do lado de fora do refeitório. No caminho de Issa ao refeitório, há uma pequena escada de três degraus. Ao se aproximar da escada, Issa reclina seu corpo para frente, como que para apoiar-se com as mãos nos degraus, para subi-la. Ao fazer esse movimento, a educadora rapidamente intervém, pegando Issa no colo e a colocando de pé já no último degrau.

Episódio 2. Issa e o seu Lugar Reservado à Mesa. Quando chega ao refeitório, a educadora que acompanha Issa diz para ela se sentar em um banco no meio do salão. Faz isso segurando-a pelo braço e colocando-a ali sentada. Após isso, a educadora ouve a cozinheira dizendo que é para Issa se sentar em outro lugar, próximo à parede. Issa volta seu rosto para a cozinheira. A educadora se levanta e se posiciona ao lado do banco em que a menina está sentada, dizendo: "É para sentar lá, que é melhor". A cozinheira, entrando no refeitório, fala em voz alta, estridente e em tom de repreensão: "Issa! Issa! Issa!" Fala ainda para que Issa se sente em seu lugar de "costume", exclamando: "Seu lugar é aqui!" Issa levanta-se, mas faz os movimentos de forma lenta, buscando apoiar-se frente aos desequilíbrios do corpo. Porém, quando a cozinheira vê Issa parada e apoiada na mesa, vai até ela, pega-a bruscamente pelo braço e a puxa até um banco encostado na parede, perto da fila onde estavam os demais alunos. Diz: "Senta aqui! Você não sabe que aqui é o seu lugar? Fica aqui!"

Episódio 3. "Burlando" a Fila do Lanche. Após o ingresso das demais crianças no refeitório, elas se enfileiram para pegar a comida. Em determinado momento, a educadora aponta para a fila de crianças e diz para Issa ficar na mesma, para pegar o pão. A educadora diz: "Vai lá!" Issa vai se levantando, olhando para as demais crianças e dirigindo-se para o final da fila, andando com certo desequilíbrio e tocando as crianças com leveza, a fim de apoiar-se. Nesse momento, a educadora a chama e diz "Aqui!" indicando para Issa entrar no meio da fila. Para isso, a educadora pede para uma criança, em tom brincalhão: "Deixa ela entrar na sua frente?!" As crianças a deixam entrar no meio da fila. No entanto, não conversam com ela. A educadora abre mais um espaço para Issa no meio das crianças, pedindo novamente para uma delas deixá-la se acomodar melhor.

Um primeiro ponto a ser discutido é que Issa é a única criança com alguma deficiência da instituição e ela está em meio ao processo de inclusão, processo este regulamentado por lei, mas novo e controverso para a educação, a qual ainda não construiu instrumentos para efetivá-lo adequadamente. Nesse contexto, Issa ingressa. Porém, em função da paralisia cerebral, ela apresenta o com- 
prometimento em uma série de habilidades - dificuldade de equilíbrio, para andar e manipular coisas; dificuldade de controle da saliva e esfinctérico; dificuldade de fala. Esses aspectos ocorrem dentro de uma sociedade em que a regra geral tem sido "normalizar," no sentido de indicar padrões de normalidade de comportamento e desenvolvi-mento, além de tempos para sua aquisição (Canguilhem, 2002). Nesse contexto escolar, o perfil de Issa destoa. É a partir desse referencial que ela é vista e, simultaneamente, é a partir das suas limitações e potencialidades que ela experiencia as pessoas e relações ao seu redor, constituindo-se.

Detalhando a análise, em função das significações atribuídas à diferença no funcionamento e desenvolvimento da criança, no contexto, amplifica-se a diferenciação em relação a ela, o que pode ser observado pelo lugar em que Issa é colocada no ambiente: ela entra antes que as demais crianças, por uma outra entrada e sem ter que enfrentar a fila comum às crianças; ainda, deve se sentar em um local bastante específico da sala, em uma determinada posição no banco; finalmente, ela pode burlar a fila na hora de pegar o lanche.

As intervenções da educadora/cozinheira mostram-se carregadas de significações, marcadas pelas práticas sociais daquela cultura. Nesse sentido, ela acaba ocupando uma posição e/ou é colocada em uma posição diferente da de seus coetâneos. E como a criança possui "necessidades especiais," a educadora e a cozinheira extrapolam a questão do cuidado auxiliando-a em situações que, aparentemente, não necessitariam de atenção especial (como no caso pegar no colo para subir os degraus da escada).

Porém, as ações desses adultos resultam na possibilidade de realização ou não de determinadas atividades por Issa. Assim, não deixar Issa realizar sozinha a atividade, por exemplo, pode indicar desrespeito ao tempo da criança ou a subestimação de sua capacidade de desempenhar atividades aparentemente complexas. Pode estar relacionada, ainda, à concepção de cuidado, superprotegendo a criança. Independentemente do(s) motivo(s), tais ações inclusive podem acabar impedindo a criança de desenvolver novas aprendizagens, como ocorreria com uma criança sem deficiência. É nesse espaço disponibilizado pelos parceiros que ela passa a ter ou não possibilidade de aquisição de diferentes habilidades ou o aprimoramento de algumas habilidades que estariam mais comprometidas.

A diferença não é dada pela criança, mas pelas educadoras, a partir das características físicas da criança. Issa indica, por exemplo, que vai seguir a regra e dirige-se ao final da fila para pegar comida. É a intervenção da educadora que faz com que ela entre no meio da fila. Retomando-se as ideias de Bakhtin (1999), a realidade social partilhada por essas crianças e esses adultos é essencial para tornar o processo de comunicação e relação capaz de produzir atos de fala carregados de significações. Os saberes coletivos relativos a desenvolvimento, escola, deficiência e inclusão estão presentificados na postura da educadora e, também, da cozinheira. O trabalho coletivo e ininterrupto de sujeitos socialmente organizados instaura a construção, também coletiva, de posições no mundo, conhecimentos e saberes sobre o mundo e o outro no cotidiano das relações.

Essa diferença pode, no entanto, ser minimizada, sendo negociado um outro papel pela criança com seus parceiros. Mas essa negociação depende do modo como é interpretada. No caso, Issa compreende o que as outras pessoas the dizem e atende às ordens das educadoras (como limpar a "baba", sentar-se corretamente, trocar de lugar, fechar a boca), parecendo ser capaz de ter um papel mais ativo. Apesar disso, pouco é ouvida. Puxamna bruscamente, pegam-na no colo, falam por ela com os colegas na fila, quase que buscando ocupar seu lugar, por que a compreendem como incapaz, em função da sua dificuldade de fala.

Mas se nos ativermos apenas à consideração da baixa comunicação verbal da criança, poderemos cair no erro de afirmar que há um reduzido contato de Issa com os demais pelo seu déficit verbal. Como discutido por Bakhtin (1999), não apenas a linguagem verbal mostrase relevante e portadora de significação. Assim, quando se observam as interações da criança utilizando-se de linguagens não-verbais (quando Issa está na fila e olha, toca levemente nas crianças, vacila ou se coloca timidamente frente à entrada no meio da fila, por exemplo), verificamos que a criança apresenta habilidade comunicativa, carregada de expressividade. Toda essa expressividade corporal vem no contraponto a dos demais (no caso, da cozinheira, educadora e demais crianças), contribuindo para construir um diálogo mudo por parte da criança com seus outros sociais. Esse diálogo mostrase carregado de sentidos que fazem com que Issa fique alijada, deslocada ou em posição de estranhamento do conjunto em que está inserida.

A partir do caso analisado, no diálogo entre cultura e biológico, emerge um palco de vivências e discursividades. E, com isso, a grande contradição que se verifica é o quanto esses múltiplos sentidos geram a dialética da inclusão/exclusão (Sawaia, 2002) da criança naquele ambiente; o quanto a criança, apesar de incluída na escola, acaba por se manter/ser mantida excluída do convívio e das práticas usuais que abarcam as outras crianças. São tais aspectos, apreendidos pelas suas experiências concretas - por meio do local onde fica (e da perspectiva que isso lhe dá de si e do mundo), pelo modo com que é segurada, tocada, puxada, que vão constituir $a$ e ser constituídas pela corporeidade da criança, na interação com o outro, como apontado no conceito de corporeidade trazido por Polak (1997).

\section{O Estudo de Laura}

Laura é filha única e de uma família de camada social baixa. Em relação ao seu diagnóstico, um profissional de saúde afirma que ela possui uma Paralisia Cerebral hipotônica (com uma flacidez muscular), enquanto ou- 
tro afirma que a menina possui uma disparesia espástica (quando os membros superiores apresentam melhor função que os inferiores, apresentando também um aumento do tônus muscular e hiperreflexia). Segundo Yazlle (2001), seus pais a incentivam e sempre a ajudam a se movimentar ("ensinar a andar"), já que Laura ainda não anda de forma independente. Assim, Laura é geralmente transportada pela mãe, ou no colo ou em um carrinho de bebê. Laura tem um desenvolvimento normal da fala.

Episódio 1. Presença da Mãe de Laura na Pré-Escola. As crianças estão aguardando para entrar no refeitório da pré-escola. Entre as crianças e as educadoras, está a mãe de Laura, que segura a filha no colo enquanto esperam. Os alunos vão se dirigindo para o refeitório, esboçando uma pequena fila, que se divide entre a de meninos e a de meninas. As crianças vão entrando no saguão anterior ao refeitório, Marta (mãe) indo mais atrás. Algumas crianças acompanham Marta, umas encostando-se em Laura, tentando tocá-la. Quando esta é tocada nos pés, Laura olha para baixo e abre bastante os olhos, com ar de curiosidade. Porém, não fala ou sorri, permanecendo bastante séria. A mãe sorri e continua o seu trajeto com a filha, não parando para conversar ou brincar com as crianças, nem incentivando o contato da filha com elas. Quando a câmera foca em seu rosto, o que se pode notar é o seu alto grau de observação: Laura está sempre olhando ao redor. Porém, quase não fala. Nas raras vezes em que parece falar, dirige-se à mãe, em voz baixa. Marta conversa com a filha em muitos pontos da gravação, sempre cochichando algo, não sendo audível à gravação.

Episódio 2. Laura e sua Mãe Entram no Refeitório Antes das Outras Crianças. As crianças formam, finalmente, duas filas para entrar no refeitório. Todos ficam esperando as ordens de Vitória (cozinheira) para entrar. Finalmente, a cozinheira pede para que Marta entre juntamente com Laura. Elas entram, enquanto que as demais crianças permanecem esperando do lado de fora do refeitório. Quando Vitória fala para as crianças entrarem, que o sinal já iria ser soado, Marta já está sentada em um dos bancos com a filha.

Episódio 3. A Cozinheira se Dirige à Mãe e não à Laura. Há cerca de doze crianças no salão do refeitório, sendo que todas se concentram em apenas uma das mesas (apesar de haver quatro mesas no refeitório), aquela em que se sentam Marta e Laura, as crianças ficando bem próximas a elas. A mãe de Laura a apoia pelas costas, envolvendo-a com um dos braços, a fim de que a criança não se desequilibre e caia (os bancos não têm apoio para as costas). Depois de orientar e supervisionar as demais crianças, incentivando-as a pegar a comida e a se alimentar sozinhas, a cozinheira leva um prato de macarronada para Laura. Ela o coloca diante da criança e, dirigindo-se à mãe, diz que colocou "um tanto" e que, se ela quiser mais, poderia pedir. Neste momento, Laura olha para a cozinheira, que não a olha. Marta também se volta à cozinheira, agradecendo-a, timidamente.
Como visto, no caso de Laura, repete-se a situação de Issa, no que se refere ao quanto, a partir da relação entre biológico e cultural, vão sendo construídos sentidos, práticas e a própria subjetividade da criança. Nesse caso, alguns outros pontos merecem ser destacados e discutidos mais profundamente, dada a visibilidade que têm.

Novamente, o que se coloca é a interpretação que se faz da criança, em função das considerações sobre sua diferença. No caso, Laura apenas estabelece contato verbal com a mãe, o qual não é possível de ser captado pela gravação, dados os ruídos do ambiente e o baixo tom de voz das duas. Pode-se apenas ver o movimento dos lábios de Laura no ouvido da mãe. A menina, em nenhum momento, fala com seus colegas de turma ou com as educadoras presentes. Pode-se retomar, assim como discutido no caso de Issa, que o tom de voz e a privacidade do que é dito é significativo, sendo simultaneamente constituído pelo contexto e constituindo as relações da criança naquele contexto. A entonação expressiva ou mesmo o silêncio carregam sentidos que são expressos na situação registrada, na relação entre mãe e filha, no ambiente pré-escolar que as coloca como à parte do conjunto.

Tal aspecto pode ser visto, por exemplo, no contraponto do modo de lidar da cozinheira com as crianças. Assim, por um lado, a cozinheira delega responsabilidades aos alunos, como a de eles mesmos pegarem a comida, escolherem o local onde querem se sentar e recolherem seus pratos e talheres. Porém, contrariamente ao modo como lida com o conjunto de crianças, se dá a relação com Laura. O que a diferencia, nesta situação, é que todas as crianças possuem autonomia para levantar e buscar o alimento, ao passo que Laura precisa esperar, a fim de que a cozinheira venha até ela. Não se nota qualquer movimento da mãe no sentido de se levantar e buscar comida para a filha, nem de levá-la até o balcão para buscar o alimento juntamente com ela, para que a menina escolha o que quer comer. Mãe e filha permanecem sentadas e aguardando, tal posição estando carregada de sentidos não ditos. A mãe medeia, assim, o comportamento da criança, indicando que se deva esperar.

Ainda, o que se observa é que a própria cozinheira prepara o prato para Laura. Mais do que isso, a cozinheira não se dirige diretamente à criança, mas à mãe. Assim, a cozinheira fala por meio de Marta e lhe atribui a decisão do que Laura deve comer, de quanto comer e de quando se saciar, apesar de Laura não ter prejuízo no que concerne ao seu desenvolvimento da fala e compreensão.

Laura é tratada, com isso, como se fosse incapaz de ter preferências ou mesmo incapaz de decidir e se posicionar. À Laura não é dado poder de voz, ao contrário dos colegas de turma. Ela acaba por ser colocada em posição de incompetência. Em uma possível generalização de sua deficiência, Laura é vista/tida como incapaz de decidir o que quer comer, e mesmo se quer comer (há crianças que, por exemplo, vão ao refeitório e não se alimentam). 
Laura acaba ocupando uma determinada posição na situação que se regula a partir da presença da mãe, já que mesmo seus coetâneos se dirigem, na maioria das vezes, a Marta, e não à Laura.

Notadamente no caso de Laura, são as suas características físicas (a falta de autonomia da locomoção, além de algumas dificuldades motoras) e um discurso social forte (diagnóstico clínico - Paralisia Cerebral - e de deficiência) que constroem o subsídio para as práticas discursivas que se voltam a ela, corporificando-se na sua forma de ser e de se relacionar. No conjunto da interpretação social, a deficiência motora resulta na consideração da criança como totalmente deficiente. A parte é tomada pelo todo. Esse recorte faz com que os adultos interpretem que, frente a isso, há a necessidade de se criarem condições especiais de atendimento.

Nesse sentido, o contato físico-social de Laura com o ambiente se dá pela interlocução corpórea da mãe, que a segura no colo e, fisicamente, a dirige para e por uma série de ambientes e atividades. Ponto central a ser discutido aqui é a presença da mãe de Laura na escola. Como indicado no trabalho de Yazlle (2001), a sua presença é exigida pela escola, que justifica que a criança precisaria da mãe nos primeiros dias, para se adaptar à nova rotina; e, também, a escola precisaria da mãe para "cuidar" da menina, posto que a instituição dizia não poder se encarregar dessa tarefa. Assim, à mãe, cabe o papel de "cuidar" da filha, mesmo na escola. Cuidar, pois a escola compreendia que seu papel seria o de "educar," como se cuidar e educar fossem funções que pudessem se desvencilhar (Kuhlmann, 1998).

Nesse papel, a mãe intermedeia as mais diferentes experiências da filha naquele contexto. Laura permanece no colo da mãe, mesmo a criança aparentando estar um pouco grande para a mãe segurá-la durante muito tempo. Ainda, ao se alimentar, Laura tenta pegar a colher logo que a vê, ao que Marta não lhe dá tempo para que ela se ajuste e consiga realmente segurar a colher e se alimentar de modo independente. Marta é quem a alimenta na boca, quem acaba por realizar a tarefa para e pela filha. Neste contexto, Laura, que busca comer sozinha, não é incentivada a ter autonomia para se alimentar. A própria cozinheira que as observa não faz esse movimento. Apesar de não se perceber se a menina tem real inabilidade para manusear a colher e comer, Laura é colocada na posição de ser incapaz para desempenhar essa tarefa.

A mãe circunscreve ainda as relações com os parceiros, naquele contexto. Nesse sentido, destaca-se o modo como a menina lança seu olhar ao ambiente e aos seus parceiros de interação. Laura está sempre atenta e olhando com muito interesse para o ambiente, dentro de seus recursos e possibilidades. Quando alguma criança a chama, Laura volta seu tronco a ela, a fim de visualizá-la. No entanto, o fato de a mãe nem sempre parar para que a filha entre em contato mais próximo com as outras crianças acaba distanciando-a do grupo em certos momentos.
A este ponto, Marta destaca o contato de Laura com o mundo escolar intermediado por ela e por suas próprias concepções de relação, interação e inclusão.

Assim, o desenvolvimento de habilidades e de uma identidade, além da relação de Laura com seus outros sociais (no caso, notadamente com os colegas de turma) se dá, fundamentalmente, a partir de uma exigência da escola, pela mediação da mãe, a qual a interpenetra, estando a corporeidade de Laura atravessada pela da mãe. A corporeidade de Laura se dá por meio da intercorporeidade, como discutido por Coelho Júnior (2003). Assim, em função das características de seu corpo e do trabalho dos adultos com o mesmo, as posições da mãe e da escola significam que a criança é diferente; que ela deve ficar na posição de espera, sem autonomia; que ela deve aguardar em silêncio, devendo assentir com o que lhe é dado; deve manter-se ignorada, não olhada, não ouvida, sem direito à voz.

Dessa maneira, as experiências desse lugar - carregada, sentada, apoiada, silenciada, acabam se constituindo como base de seu "corpo vivente." As significações dessas vivências cravam-se no existir dessa criança, orientando e sendo orientadas continuamente pelo(s) outro(s), que medeiam e corporificam práticas (carregar no colo, servir depois, permitir o burlar a fila), saberes (em torno da deficiência e da generalização da mesma) e olhares (deficiência e incompetência) que podem se mostrar (mal)adaptativos, ou não, a partir do modo como as corporeidades vão sendo constituídas em seus desenvolvimentos.

Isso pode ser tomado tanto em termos das dificuldades de desenvolvimento surgidas em função do comprometimento físico e de sua repercussão nas interações estabelecidas, quanto das potencialidades que podem ser despertadas pelo mesmo quadro, a depender do modo como a criança e o meio (ambiente, pessoas e situações) puderem se constituir e ressignificar ao longo do desenvolvimento.

\section{Comentários Finais}

A partir de nossos dados empíricos e das discussões, constatamos que os discursos e as significações se encontram justamente corporificados nos participantes, pois são as concepções de cuidado da mãe, da educadora e da cozinheira, por exemplo, que fazem com que elas (re)ajam ou se comportem de determinados modos em relação a Issa ou a Laura. As crianças aqui estudadas vão se constituindo junto com e por meio deste(s) outro(s), que lhes trazem olhares muitas vezes diferentes, diversas formas de ser e de estar no mundo, destacando diferentes limites e possibilidades nos processos de interação e de desenvolvimento - delas e dos outros que as atravessam e as constituem. $\mathrm{O}$ gesto delas acaba por ser construído e carregado pelo gesto dos outros.

$\mathrm{O}$ contato com as diferentes realidades e percepções a partir da experiência - com o próprio corpo, com o 
corpo que é vivido, experienciado (Polak, 1997; Scorsolini-Comin, \& Amorim, 2008) traz suas nuanças, que se mesclam e se transformam constantemente no processo de interação, de apreensão do mundo e do universo dialógico da linguagem.

A corporeidade enquanto a experiência de um corpo vivido vai se dando a partir de outras corporeidades (da mãe, das funcionárias, dos coetâneos), de outras experiências que extrapolam e englobam a criança corporificada (experiências com a criança com necessidades especiais ou em relação a ela). Discute-se, assim, com base nos dados aqui obtidos, que a corporeidade de outrem participa do modo como se apresenta a própria corporeidade, fazendo-nos apropriar da noção de intercorporeidade proposta por Coelho Júnior (2003). Estudar os discursos (exclusivamente a partir do aspecto verbal) que incidem sobre as crianças pode mostrar apenas o modo como são vistas, colocando-as como pessoas passivas e sem muitas possibilidades de negociação, de responsividade em relação ao outro e ao ambiente. Porém, pelos casos aqui trazidos, verifica-se a importância de se olhar para o aspecto não-verbal na discussão da linguagem (Bakhtin, 1999). As análises revelam que, com a noção de expressividade, abre-se a possibilidade de a criança com necessidades especiais "expressar a sua voz" e ser ouvida.

Considerando esta linha de pensamento e considerando os limites e as possibilidades que emergem da criança com Paralisia Cerebral no contato com outrem, a partir da noção de corporeidade, abrem-se mais formas de conceber, analisar e discutir não só o desenvolvimento da criança e de seus pares, como a própria inclusão, seus atores, contextos e instituições. Estudando os processos dessas crianças em interação com os outros, destacamos que não são apenas as crianças com Paralisia Cerebral que se desenvolvem, mas também seus parceiros, que se modificam nas situações, no interjogo de vozes, práticas e posturas (Rossetti-Ferreira et al., 2004). O advento da criança com necessidades especiais em um meio que não estava preparado para recebê-las (não contando com adaptações ou estruturas voltadas para a inclusão) promove uma série de rearticulações no ambiente, como a preocupação das educadoras, dos funcionários, dos familiares, das demais crianças que se adaptam ao novo contexto e com as novas demandas que acabam surgindo (Yazlle, 2001).

Com essas observações, propõe-se uma abordagem para os estudos da área, resgatando o papel do corpo enquanto agente e possuidor-produtor de significações e não como um mero receptáculo de influências. A consideração do contexto e dos outros é de fundamental importância ao se discutir a corporeidade, mas isso não pode ser tomado como um modelo fechado, mas justamente aberto a outras contribuições, o que nos coloca na mesma direção da perspectiva de Morin (1990), que vê o conhecimento como algo sempre inacabado e aberto a novos diálogos. O percurso desse estudo propõe-se a con- tinuar tal discussão, no sentido de promover reflexões acerca do modo de se conceber o ser humano e a sua relação com o mundo e com o(s) outro(s), contribuindo e instrumentalizando não apenas a realização de outros estudos empíricos na área de Desenvolvimento Humano, mas também para a consideração de tais elementos e de tais perspectivas nos estudos já em andamento, em diferentes áreas do conhecimento.

\section{Referências}

Amorim, K. S. (2002). Materialização de discursos e práticas histórico-sociais, em situações de freqüência e de adoecimento de bebês em creche. Tese de Doutorado nãopublicada, Faculdade de Medicina, Universidade de São Paulo, Ribeirão Preto, SP.

Bakhtin, M. (1997). Estética da criação verbal (2. ed., M. E. G. G. Pereira, Trad.). São Paulo, SP: Martins Fontes.

Bakhtin, M. (1999). Marxismo e filosofia da linguagem (9. ed., M. Lahud \& Y. F. Vieira, Trads.). São Paulo, SP: Hucitec.

Canguilhem, G. (2002). O normal e o patológico (5. ed.). Rio de Janeiro, RJ: Forense Universitária.

Coelho Júnior, N. E. (2003). Da intersubjetividade à intercorporeidade: Contribuições da filosofia fenomenológica ao estudo psicológico da alteridade. Revista Psicologia USP, 14, 185-209.

Constituição da República Federativa do Brasil. (1988, 5 out.). Retrieved November 6, 2008 from http://www.senado.gov.br/ sf/legislacao/const/

Declaração de Salamanca. (1994). In Conferência Mundial de Educação Especial. Salamanca, Espanha: Organização das Nações Unidas. Retrieved from http://portal.mec.gov.br/ seesp/arquivos/pdf/salamanca.pdf

Faraco, C. A. (1996). O dialogismo como chave de uma Antropologia Filosófica. In C. A. Faraco, C. Tezza, \& G. Castro (Eds.), Diálogos com Bakhtin (pp. 113-126). Curitiba, PR: Editora da Universidade Federal do Paraná.

Fogel, A. (2000). O contexto sociocultural e histórico dos estudos do desenvolvimento. Psicologia: Reflexão e Crítica, 13, 311-318.

Góes, M. C. R. (2000). A Abordagem microgenética na matriz histórico-cultural: Uma perspectiva para o estudo da constituição da subjetividade. Cadernos Cedes, 20(50), 9-25.

Hoogland, R. (2002). Fact and fantasy: The body of desire in the age of posthumanism. Journal of Gender Studies, 11, 213-231.

Kuhlmann, M., Jr. (1998). Infância e educação infantil: Uma abordagem histórica. Porto Alegre, RS: Mediação.

Lei n. 9.394, de 20 de dezembro de 1996. (1996, 23 dez.). Lei de Diretrizes e Bases. Diário Oficial da União, seção 1.

Morin, E. (1990). Introdução ao pensamento complexo (2. ed.). Lisboa, Portugal: Instituto Piaget.

Overton, W. (1997). Beyond dichotomy: An embodied active agent for Cultural Psychology. Culture and Psychology, 3, 315-334.

Paterson, K., \& Hughes, B. (1999). Disability studies and phenomenology: The carnal politics of everyday life. Disability and Society, 14, 597-610.

Polak, Y. N. S. (1997). O corpo como mediador da relação homem/mundo. Texto \& Contexto Enfermagem, 6(3), 29-43.

Resolução 45/91. (1990, 14 dez.). Destaca o termo "uma sociedade para todos" e estabelece o ano de 2010 como meta 
para se concluir uma sociedade para todos. New York: Organização das Nações Unidas.

Roriz, T. M. S., Amorim, K. S., \& Rossetti-Ferreira, M. C. (2005). Inclusão social/escolar de pessoas com necessidades especiais: Múltiplas perspectivas e controversas práticas discursivas. Psicologia USP, 16, 167-194.

Rossetti-Ferreira, M. C., Amorim, K. S., Silva, A. P. S., \& Carvalho, A. M. A. (Eds.). (2004). Rede de significações e o estudo do desenvolvimento. Porto Alegre, RS: Artmed.

Rossetti-Ferreira, M. C., Amorim, K. S., Soares-Silva, A. P., \& Oliveira, Z. M. R. (2008). Desafios metodológicos na perspectiva da rede de significações. Cadernos de Pesquisa, 38(133), 147-170.

Sawaia, B. (2002). As artimanhas da exclusão: Análise psicossocial e ética da desigualdade social (4. ed.). Petrópolis, RJ: Vozes.

Scorsolini-Comin, F. (2006). "Em meu gesto existe o teu gesto e em minha voz a tua voz": Discutindo a corporeidade de crianças em processos de inclusão pré-escolar. Monografia não-publicada, Faculdade de Filosofia, Ciências e Letras, Universidade de São Paulo, Ribeirão Preto, SP.

Scorsolini-Comin, F., \& Amorim, K. S. (2008). Corporeidade: Uma revisão crítica da literatura científica. Psicologia em Revista, 14(1), 189-214.

Valsiner, J. (1987). Culture and the development of children's action: A Cultural-Historical Theory of Developmental Psychology. New York: Wiley.

Yazlle, C. H. D. (2001). Pré-escolas convivendo com a paralisia cerebral: Uma análise do processo de inclusão/exclusão. Dissertação de Mestrado não-publicada, Faculdade de Medicina, Universidade de São Paulo, Ribeirão Preto, SP.

Yazlle, C. H. D., Amorim, K. S., \& Rossetti-Ferreira, M. C. (2004). A RedSig como recurso metodológico na investigação do processo de inclusão de crianças portadoras de paralisia cerebral na pré-escola. In M. C. Rossetti-Ferreira, K. S. Amorim, A. P. S. Silva, \& A. M. A. Carvalho (Eds.), Rede de significações e o estudo do desenvolvimento humano (pp. 190-206). Porto Alegre, RS: Artmed.

Yin, R. (2005). Estudo de caso: Planejamento e métodos (3. ed.). São Paulo, SP: Bookman. 